\title{
Long-term results of glaucoma drainage device surgery
}

\author{
Konstantine Purtskhvanidze ${ }^{*}$ (D), Mark Saeger, Felix Treumer, Johann Roider and Bernhard Nölle
}

\begin{abstract}
Background: To evaluate long-term results of eyes with glaucoma drainage device (GDD).

Methods: We retrospectively reviewed medical records of all patients who underwent GDD placement at our institution between 2001 and 2014. A total of 110 eyes of 90 patients were studied. Glaucoma outcome was assessed by postoperative intraocular pressure (IOP), number of medications, and need for further glaucoma surgery. Surgical procedures before and during the study period, and their complications were evaluated.

Results: The mean follow-up was $78.3 \pm 44.0$ months. The mean preoperative intraocular pressure was $30.8 \pm 6.9 \mathrm{mmHg}$ with $3.5 \pm 1.1$ glaucoma medications. At last postoperative follow-up, the mean IOP decreased to $14.3 \pm 5.4 \mathrm{mmHg}$ with $1.6 \pm 1.5$ glaucoma medications. GDD implantation successfully controlled glaucoma in $86,85,81,78,79,76$ and $73 \%$ of eyes at 1, 2, 3, 4, 5, 7 and 10 years, respectively. At last follow-up IOP was successfully controlled in $67 \%$ of eyes. Clinical complications occurred in $56.4 \%$ of eyes during the follow-up period.
\end{abstract}

Conclusions: A glaucoma drainage device can successfully control intractable glaucoma even after a very long period of time.

Keywords: Ahmed valve, Baerveldt implant, Glaucoma surgery, Glaucoma drainage device, IOP control

\section{Background}

Glaucoma is a leading cause of blindness worldwide [1]. Intraocular pressure (IOP) lowering is the only proven method to prevent the development [2] and/or slow the progression of glaucomatous optic neuropathy [3]. The conventional approach is to attempt medical therapy or laser trabeculoplasty prior to surgery.

Recently, the use of glaucoma drainage devices (GDDs) has become a widely used therapy option for the management of eyes with complicated glaucoma refractory to standard trabeculectomy with adjunctive antifibrotics. This trend is following the results of the Tube Versus Trabeculectomy study, which reported a better success rate at 5 years with Baerveldt implantation than with trabeculectomy with mitomycin-C in patients who had undergone previous surgery [4].

Since Molteno's introduction in 1969 different modified types of drainage devices, which differ in surface area, shape, composition, and presence or absence of a flow-restricting valve are currently used [5]. Two of the most common devices are the valved Ahmed Glaucoma Valve (AGV; New World Medical, Rancho Cucamonga, CA, USA) and the non-valved Baerveldt Glaucoma Implant (BGI; Abbott Medical Optics, Abbott Park, IL, USA). These devices have been shown to be effective in lowering IOP for the treatment of glaucoma in patients with a variety of glaucomas in whom medical therapy or multiple trabeculectomies have failed or are expected to have a very low chance of surgical success [6-9]. The surgical success rates are dependent on the length of follow-up, success criteria, and different types of glaucoma. They vary from 68 to $100 \%$ for the Ahmed Glaucoma Valve and from 43 to $100 \%$ for the Baerveldt Glaucoma Implant [5].

In this study, we present long-term follow-up results of eyes with glaucoma drainage device. In addition, all relevant clinical factors were evaluated for their association with glaucoma outcome.

\section{Methods}

The medical records of all patients who underwent GDD placement (Baerveldt or Ahmed) at the Department

\footnotetext{
* Correspondence: konstantine.purtskhvanidze@uksh.de

Department of Ophthalmology, University Medical Center

Schleswig-Holstein, Arnold-Heller Strasse 3, Haus 25, D-24105 Kiel, Germany
}

(C) The Author(s). 2019 Open Access This article is distributed under the terms of the Creative Commons Attribution 4.0 International License (http://creativecommons.org/licenses/by/4.0/), which permits unrestricted use, distribution, and reproduction in any medium, provided you give appropriate credit to the original author(s) and the source, provide a link to the Creative Commons license, and indicate if changes were made. The Creative Commons Public Domain Dedication waiver (http://creativecommons.org/publicdomain/zero/1.0/) applies to the data made available in this article, unless otherwise stated. 
of Ophthalmology of the University Medical Center Schleswig-Holstein Campus Kiel between 2001 and 2014 were retrospectively reviewed. Patients who underwent a penetrating keratoplasty prior to GDD implantation were excluded.

One hundred ten eyes of 90 patients were included in this study. Study criteria required a minimum of 2-year follow-up. Collected data included demographic information, type of glaucoma, type of corneal pathology, number and type of previous ophthalmic surgeries, complications, preoperative and postoperative best-corrected visual acuity, preoperative and postoperative IOP, number and type of glaucoma medications. Surgical outcome was assessed in terms of adequacy of IOP control. Success for glaucoma control was defined as a postoperative IOP $\geq 5 \mathrm{mmHg}$ and $\leq 21 \mathrm{mmHg}$ with or without application of antiglaucoma medications, with no need for further glaucoma surgery and without loss of light perception at last follow-up. Combination medication eye drops were counted as 2 medications. An oral carbonic anhydrase inhibitor was counted as 1 additional medication. Visual acuity was measured with the Snellen vision chart. For numerical analysis, Snellen visual acuity was converted to logarithm of the minimum angle of resolution (logMAR) values using the equitation: $\log M A R=-\log$ (visual fraction).

\section{Surgical technique}

All glaucoma surgical procedures were carried out by the same experienced surgeon (B. N.) of the Department of Ophthalmology. GDDs used in this study were Ahmed ${ }^{\mathrm{mw}}$ Glaucoma Valve (FP7 AGV; New World Medical, Rancho Cucamonga, CA, USA) and Baerveldt $\left(250 \mathrm{~mm}^{2}\right.$ BGI; Abbott Medical Optics, Abbott Park, IL, USA). The surgical techniques of GDD implantation have been decribed in detail by others before $[10,11]$. Briefly, a limbus based conjunctival peritomy was done with a blunt dissection down to bare sclera in 2 to 3 quadrants. Implants were placed between the lateral rectus and the superior rectus if possible. For Baerveldt implants a 7-0 vicryl ligature suture was placed to form a watertight seal around the tube. GDD plates were secured to sclera with $7-0$ prolene sutures. A limbal tract was created with a 23 -gauge needle. Then a prompt insertion of the tube through insertion forceps was performed. Tubes were inserted into the anterior chamber just overlying the iris without touching the cornea. In eyes where the tube was positioned in the pars plana, a pars plana vitrectomy (PPV) was performed. A scleral fistula was created 3.0 to $3.5 \mathrm{~mm}$ posterior to the corneoscleral limbus using a 22- or 23-gauge needle directed parallel to the iris plane. In cases of anterior chamber tube positioning the tube was placed within the sclera, for about one third of its length. Therefore no xenogeneic or other tissue was used for coverage. Tubes were secured to the sclera with $1-3$ interrupted $10-0$ nylon sutures.
The conjunctiva and Tenon's tissue were sutured in single layer using 8-0 vicryl sutures. At the end of GDD surgery no leakage was observed in any of the eyes. A subconjunctival injection of dexagentamicin was given at the end of surgery. Postoperative topical medications included antibiotics and corticosteroids depending on the degree of intraocular inflammation. The medication was tapered to a low dose over several months. If necessary, glaucoma medications were added to control IOP.

\section{Statistical analysis}

The statistical analyses were performed using the SPSS software (IBM SPSS Statistics, Version 24). Univariate analysis was performed using the log-rank test for comparing Kaplan-Meier survival curves. For preoperative and postoperative analyses, the Wilcoxon signed-rank

Table 1 Patient Demographic Data

\begin{tabular}{|c|c|}
\hline Number of Patients & 90 \\
\hline Number of Eyes & 110 \\
\hline Age range (mean $\pm S D)$, y & $2-87(47.9 \pm 24.4)$ \\
\hline \multicolumn{2}{|l|}{ Sex } \\
\hline Male & $35 / 90(38.9)$ \\
\hline Female & $55 / 90(61.1)$ \\
\hline \multicolumn{2}{|l|}{ Glaucoma type } \\
\hline Primary open angle & $50 / 110(45.5)$ \\
\hline Chronic angle closure & $1 / 110(0.9)$ \\
\hline Congenital & 18/110 (16.4) \\
\hline Uveitic & 27/110 (24.6) \\
\hline Pseudoexfoliative & $5 / 110(4.5)$ \\
\hline Traumatic & 2/110 (1.8) \\
\hline Iridocorneal endothelial Syndrom & 2/110 (1.8) \\
\hline Aphakia & 4/110 (3.6) \\
\hline Pigmentary & $1 / 110(0.9)$ \\
\hline \multicolumn{2}{|l|}{ Pre-GDD lens status } \\
\hline Aphakic & $17 / 110(15.5)$ \\
\hline Phakic & $35 / 110(31.8)$ \\
\hline $\mathrm{PCIOL}$ & $58 / 110(52.7)$ \\
\hline \multicolumn{2}{|l|}{ Ocular surgeries pre-GDD } \\
\hline Range (mean $\pm \mathrm{SD}$ ) & $1-8(2.7 \pm 1.4)$ \\
\hline Trabeculectomy & $92 / 110(83.6)$ \\
\hline Phaco/PCIOL & $57 / 110(51.8)$ \\
\hline Pas plana vitrectomy & $12 / 110(10.9)$ \\
\hline Trabeculectomy revision & $14 / 110(12.7)$ \\
\hline Anterior vitrectomy, lensectomy & 13/110 (11.8) \\
\hline Diode cyclophotocoagulation & $31 / 110(28.2)$ \\
\hline Cyclocryo & $7 / 110(6.4)$ \\
\hline Scleral buckle procedure & $1 / 110(0.9)$ \\
\hline
\end{tabular}

$G D D$ glaucoma drainage device, $P C I O L$ posterior chamber intraocular lens 


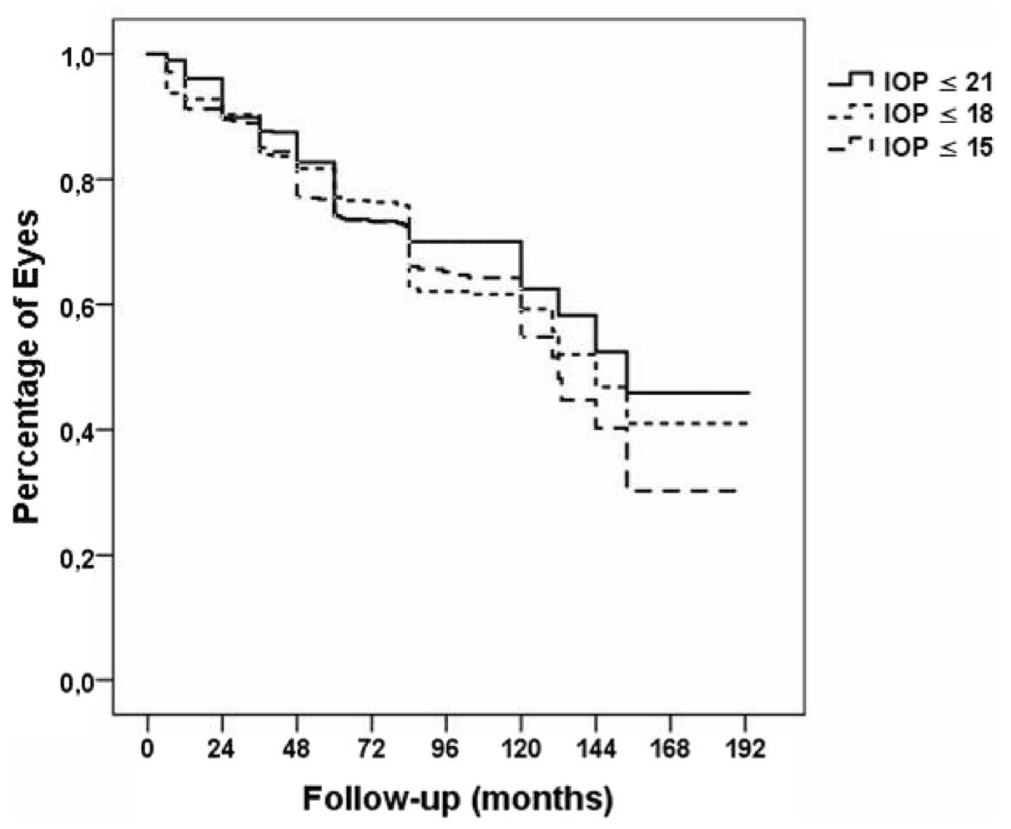

Fig. 1 Kaplan-Meier survival analysis of IOP (intraocular pressure)

test, and the Wilcoxon rank sum test (U-test) were used for measured data. The Fisher exact test was used for nominal scaled data. A $p$-value less than 0.05 was considered statistically significant.

\section{Results}

A total of 110 eyes of 90 patients were included. The demographic data and preoperative clinical characteristics of the study patients are presented in Table 1 . The mean patient age was $47.9 \pm 24.4$ years (range, $2-87$ ). The mean follow-up was $78.3 \pm 44.0$ months (range, 24-193). Glaucoma diagnoses were divided into different types.

One hundred one (91.8\%) Ahmed implants and 9 (8.2\%) Baerveldt implants were used. Eighty-three (75.5\%) implants were placed in the anterior chamber, and 27 (24.5\%) implants were positioned in the pars plana. The number of performed surgical procedures before the study period was $2.7 \pm 1.4$ (Table 1). During the study period the number of additionaly performed surgical procedures was $1.5 \pm 1.4$ (Table 3).

\section{Glaucoma outcome}

The mean preoperative intraocular pressure was $30.8 \pm$ $6.9 \mathrm{mmHg}$. At last postoperative follow-up, the mean IOP had decreased to $14.3 \pm 5.4 \mathrm{mmHg}(p=0.001)$ (Fig. 1). The mean preoperative glaucoma medications were $3.5 \pm 1.1$. The mean glaucoma medications were $1.1 \pm 1.2,1.1 \pm 1.2$, $1.5 \pm 1.3,1.6 \pm 1.4,1.9 \pm 1.6,1.8 \pm 1.7,1.8 \pm 1.6$ at $1,2,3,4,5$, 7 and 10 years, respectively. At last postoperative follow-up, the mean glaucoma medications were $1.6 \pm 1.5(p=0.001)$ (Table 2). Overall, GDD implantation successfully controlled
Table 2 Postoperative Data

\begin{tabular}{ll}
\hline Follow-up (mo) & \\
Mean \pm SD (range) & $78.3 \pm 44.0$ (24-193) \\
Total Number of eyes at each follow-up & 110 \\
2 yrs & 92 \\
3 yrs & 80 \\
4 yrs & 68 \\
5 yrs & 52 \\
7 yrs & 23 \\
10yrs & \\
Pre-GDD IOP (mmHg) & $30.8 \pm 6.9(20-52)$ \\
Mean \pm SD (range) & \\
IOP at last follow-up visit (mmHg) & $14.3 \pm 5.4(2-34)$ \\
Mean \pm SD (range) & $3.5 \pm 1.1(1-5)$ \\
Pre-GDD glaucoma medications (number) & \\
Mean \pm SD (range) & $1.6 \pm 1.5(0-5)$ \\
Medications at last follow-up (number) & \\
Mean \pm SD (range) & \\
Pre-GDD VA & $0.7 \pm 0.6$ \\
Mean \pm SD & \\
VA at last follow-up visit & \\
Mean \pm SD & \\
\hline
\end{tabular}

GDD glaucoma drainage device, $I O P$ intraocular pressure, $V A$ visual acuity 
glaucoma in $86,85,81,78,79,76$ and $73 \%$ of eyes at $1,2,3$, 4, 5, 7 and 10 years, respectively. At last follow-up IOP was successfully controlled in $67 \%$ of eyes. The success rate of the Ahmed implant was 68\%, and of the Baerveldt implant $56 \%$ at last follow-up. However, this difference was not statistically significant $(p=0.47)$.

In terms of tube placement, the glaucoma success rate of the anterior chamber tube placement was $64 \%$, and of the pars plana tube placement $78 \%$ at last follow-up. No statistically significant difference in success rates was observed $(p=0.56)$. The overall survival of glaucoma outcome was analyzed with a KaplanMeier curve (Fig. 2).

\section{Visual acuities}

Each patient's preoperative visual acuity was compared with the visual acuity at the last follow-up. The mean pre-GDD visual acuity (in $\log M A R$ ) was $0.7 \pm 0.6$. At last postoperative follow-up, the mean visual acuity (logMAR) decreased to $0.9 \pm 0.7(p=0.002)$ (Table 2). In a comparision of visual acuitiy between first and last visits, 33 (30\%) eyes showed improvement, 20 (18\%) eyes had no change, and 57 (52\%) worsened. Of these 57 eyes where the visual acuity decreased, 20 (35\%) eyes had a corneal decompensation.

\section{Complications}

Clinical complications occurred in 62 (56.4\%) eyes during the follow-up period. Postoperative complications included corneal decompensation $(n=20,19 \%)$, encapsulated bleb $(n=27,24.5 \%)$, retinal detachment $(n=7,6.4 \%)$, GDD or tube dislocation $(n=7,6.4 \%)$, tube erosion $(n=7$, $6.4 \%)$, tube-endothelial touch or blockage $(n=5,4.5 \%)$, chronic hypotony $(n=5,4.5 \%)$, and phthisis bulbi $(n=4$, 3.6\%). Table 3 shows complications during follow-up. Overall, the rate of complications was not dependent on the tube placement $(p=0.5)$.

Five eyes had a corneal decompensation prior to GDD implantation. That is why these eyes were excluded from the statistical analysis of postsurgical corneal decompensation ( 2 eyes with anterior chamber tube placement, and 3 eyes with pars plana tube placement). During follow-up period corneal decompensation ocurred in 18 of 81 eyes $(22 \%)$ with anterior chamber tube placement, and only in 2 of 24 eyes $(8 \%)$ with pars plana tube placement $(p=$ $0.15)$. At 2-year follow-up, there was a trend towards increased corneal decompensation in eyes with anterior chamber tube placement compared to pars plana tube placement $(p=0.076)$. From the third year of the study, no difference was observed between both groups $(p=$ 0.14) (Fig. 3). Due to the fact that eyes with pars plana tube placement had a shorter follow-up (up to 108

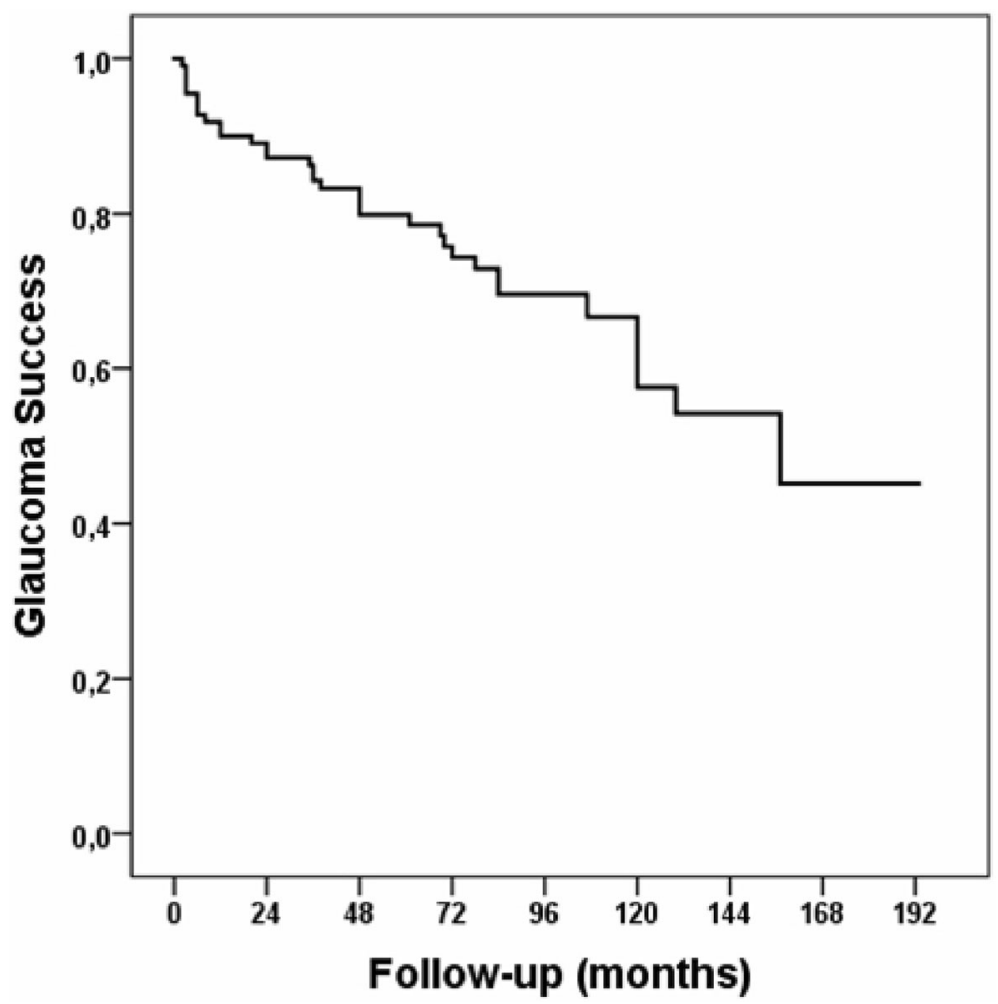

Fig. 2 Overall Kaplan-Meier survival analysis of glaucoma success throughout follow-up 
Table 3 Additional Procedures and Complications

\begin{tabular}{|c|c|}
\hline GDD type & N (\%) \\
\hline Ahmed FP7 & $101 / 110(91.8)$ \\
\hline Baerveldt $250 \mathrm{~mm}^{2}$ & $9 / 110(8.2)$ \\
\hline \multicolumn{2}{|l|}{ Location for tube placement } \\
\hline Anterior chamber & $83 / 110(75.5)$ \\
\hline Pars plana & $27 / 110(24.5)$ \\
\hline \multicolumn{2}{|l|}{ Operative and post-GDD complications } \\
\hline Corneal decompensation & 20/110 (19.0) \\
\hline Retinal detachment & $7 / 110(6.4)$ \\
\hline Encapsulated bleb & $27 / 110(24.5)$ \\
\hline GDD dislocation & $5 / 110(4.5)$ \\
\hline Tube erosion & $7 / 110(6.4)$ \\
\hline Tube dislocation & $2 / 110(1.8)$ \\
\hline Tube-endothelial touch & $3 / 110(2.7)$ \\
\hline Tube blockage & $2 / 110(1.8)$ \\
\hline Chronic hypotony ${ }^{a}$ & $5 / 110(4.5)$ \\
\hline Phthisis bulbi & 4/110 (3.6) \\
\hline No light perception & $4 / 110(3.6)$ \\
\hline Patients with complications & $62 / 110(56.4)$ \\
\hline \multicolumn{2}{|l|}{ Additional post-GDD procedures } \\
\hline Mean \pm SD (range) & $1.5 \pm 1.4(0-6)$ \\
\hline Revision of existing GDD & 2/110 (1.8) \\
\hline Tube shortening/revision & $16 / 110(14.5)$ \\
\hline Tube coverage & $5 / 110(4.5)$ \\
\hline Drainage of choroidal effusion & $5 / 110(4.5)$ \\
\hline Implantation of additional GDD & $12 / 110(10.9)$ \\
\hline GDD explantation & $3 / 110(2.7)$ \\
\hline Diode cyclophotocoagulation & $17 / 110(15.4)$ \\
\hline Phaco/PCIOL & $9 / 110(8.2)$ \\
\hline Pars plana vitrectomy & 10/110 (9.1) \\
\hline Scleral buckle procedure & $1 / 110(0.9)$ \\
\hline Needling of filtering bleb/5-FU injections & $27 / 110(24.5)$ \\
\hline Healon ${ }^{\oplus}$-injection (anterior chamber) & $26 / 110(23.6)$ \\
\hline DSAEK/PKP & 20/110 (19.0) \\
\hline Enucleation & $1 / 110(0.9)$ \\
\hline
\end{tabular}

${ }^{\mathrm{I} O \mathrm{OP}}<5 \mathrm{mmHg}$ for $\geq 3$ months

GDD glaucoma drainage device, $P C I O L$ posterior chamber intraocular lens, DSAEK descemet's stripping automated endothelial keratoplasty, 5-FU 5fluorouracil, PKP penetrating keratoplasty

months), we only compared the corneal decompensation associated with tube placement over a shorter period.

\section{Surgical procedures during study period}

During the study period the number of additional surgical procedures was $1.5 \pm 1.4$ (Table 3 ). The most commonly performed additional glaucoma procedures during the follow up period were needling of filtering bleb/5-FU injections $(n=27)$, keratoplasty $(n=20)$, tube shortening/ revision $(n=16)$, and implantation of additional GDD $(n=12)$. Overall, reoperations for complications during the follow-up were not dependent on the tube placement $(p=0.16)$. Surgical complications an additional glaucoma procedures are shown in Table 3.

\section{Discussion}

Glaucoma drainage devices are commonly used to lower IOP in patients with difficult glaucomas either as a primary surgical option or after failure of conventional filtration procedures $[12,13]$. A growing experience with these devices, improvements in the material design and surgical techniques for performing GDD implantation have also led to increased utilization in recent years [14]. Data of recently published studies, which observed the efficacy of GDDs contribute to a paradigm shift in glaucoma treatment. The TVT study shows a persistent treatment benefit of tube shunt surgery over trabeculectomy through 5 years of follow-up. At 5 years, the cumulative probability of failure was $29.8 \%$ in the tube group and $46.9 \%$ in the trabeculectomy group [4]. The results from our study demonstrated overall a cumulative probability of glaucoma failure of $21 \%$ through 5 years of follow-up. In contrast to the TVT study, which used Baerveldt implants, in our series only 9 patient received a Baerveldt implant. All other patients had an Ahmed implantation. Due to the fact that our study did not include enough patients with Baerveldt implants, it was difficult to compare the efficacy of both implants.

Three year results of the $A B C$ study [6] demonstrated a cumulative probability of failure of $31.3 \%$ in the AGV group, and of $32.1 \%$ in the BGI group. At 3 years, the AVB study [9] reported a failure rate of $51 \%$ in the AGV group and of $34 \%$ in the BGI group. In our study, patients who received the Ahmed implant showed a failure rate of $20 \%$, patients who received the Baerveldt implant showed a failure rate of $11 \%$ after a 3 year follow-up. The cumulative probabilty of failure for both implants was $19 \%$ at 3 year follow-up.

At 5 years of follow-up, the ABC study observed a cumulative probability of failure of $44.7 \%$ in the AGV group, and of $39.4 \%$ in the BGI group [6]. In our study, patients who received the Ahmed implant showed a failure rate of $22 \%$, patients who received the Baerveldt implant showed a failure rate of $11 \%$ after a 5 year follow-up. The cumulative probabilty of failure for both implants was $21 \%$ at 5 year follow-up. At last follow-up of $78.3 \pm 44.0$ months, a failure of glaucoma outcome occurred in $32 \%$ of eyes.

Rososinski et al. evaluated outcomes of pars plana versus anterior chamber placement of Baerveldt implants (anterior chamber tube placement in 34 eyes, pars plana tube placement in 29 eyes) [15]. They reported a qualified success rate at 2 years of $94 \%$ for the pars plana 


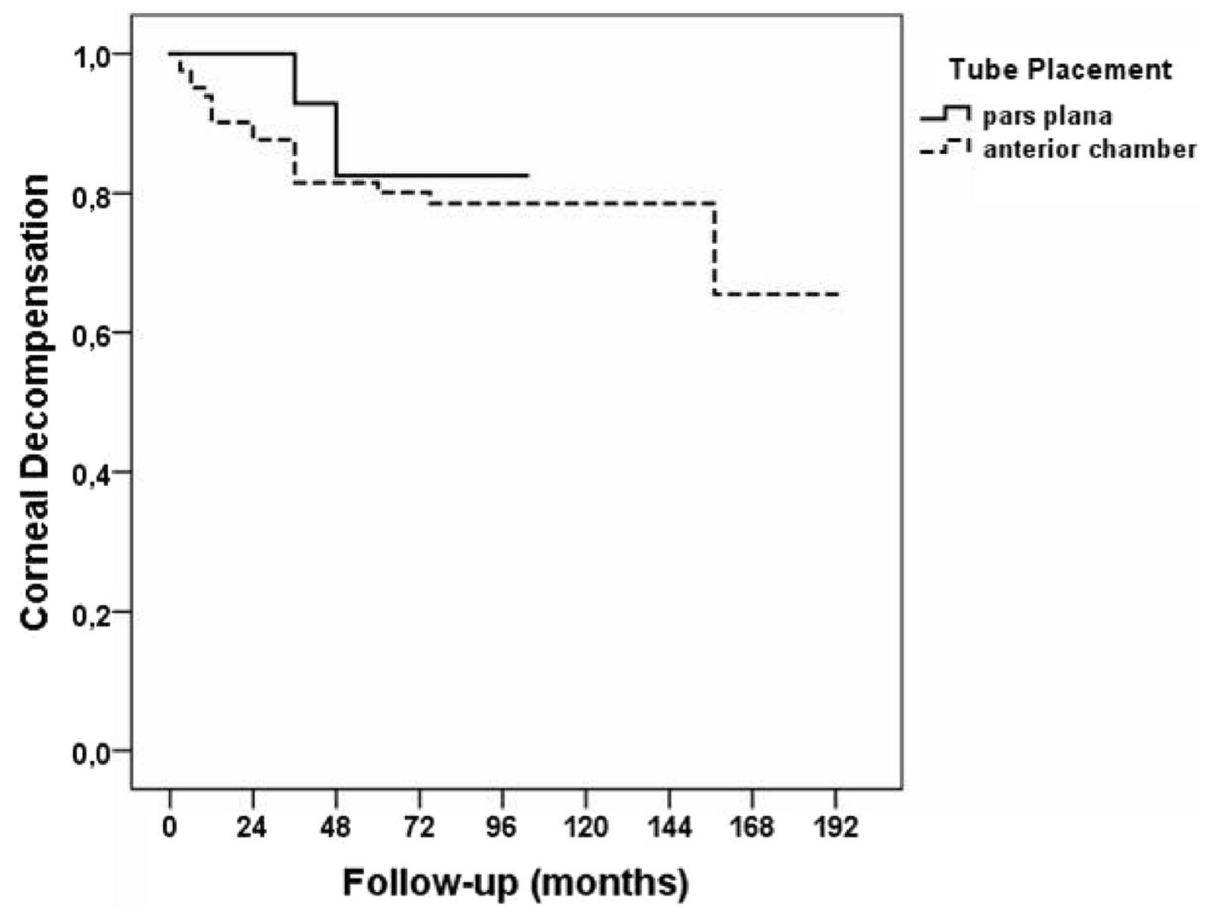

Fig. 3 Kaplan-Meier survival analysis of corneal clarity throughout follow-up

group and of $91 \%$ for the anterior chamber group [15]. In our study (anterior chamber tube placement in 83 eyes, pars plana tube placement in 27 eyes), the success rate at 2 years was $78 \%$ for the pars plana group, and $88 \%$ for the anterior chamber group $(p=0.22)$.

Guzman et al. examined the outcomes of glaucoma drainage devices (33 eyes, Molteno and Baerveldt tubes) inserted into the pars plana. They described a qualified success rate of $42.4 \%$ at 30 months [16]. In our study (27 eyes with pars plana tube placement), the success rate at 3 years was $78 \%$. At last follow-up of $78.3 \pm 44.0$ months, our results of eyes with tubes placed in the pars plana showed IOP control in $78 \%$, and in eyes with anterior chamber tube placement in $64 \%$, respectively $(p=0.56)$.

Christiakis et al. reported a postoperative complication rate of $52 \%$ at 3 year follow-up [9]. At last follow-up, we found a postoperative complication rate of $56 \%$. Rososinski et al. described no case of corneal decompensation or corneal graft failure in eyes with pars plana Baerveldt tube implantation during their 2 year follow-up period [15]. The results from our study demonstrated a corneal decompensation in 1 of 27 eyes (4\%) with pars plana Baerveldt or Ahmed tube implantation. Souza et al. experienced the complication of failed penetrating corneal keratoplasty during the 5 year follow-up period in 5\% (4 eyes) after anterior chamber Ahmed implantation [17]. In our study, at 5 years follow-up corneal decompensation occured in $19 \%$. Overall in our study, no difference was observed between eyes with anterior chamber tube placement compared to pars plana tube placement. Eyes with pars plana tube placement had a shorter follow-up. Therefore, we could only compare the tube placement over a shorter period.

There are some limitations to our study. The major limitation is its retrospective design. Further limitations are the inclusion of patients with various glaucoma diagnoses and variable severity of disease, variety of used GDDs, and different locations for the tube placement.

However, it is important to note that the sample size of this study is comparatively large. Furthermore, all surgical procedures were performed by the same surgeon. This study has a remarkably long follow-up period, which allows an assessment of long-term outcome.

\section{Conclusions}

Our study provides long-term follow-up outcomes of patients with glaucoma drainage devices. Overall, our data show that the glaucoma success with the tube implant was high. A glaucoma drainage device placement can provide effective glaucoma control even after a very long period of time.

\section{Abbreviations}

5-FU: 5-fluorouracil; $A B C$ study: Ahmed Baerveldt Comparison Study Group; AGV: Ahmed glaucoma valve; AVB study: Ahmed versus Baerveldt study; BGI: Baerveldt glaucoma implant; DSAEK: Descemet's stripping automated endothelial keratoplasty; GDD: Glaucoma drainage device; IOP: Intraocular pressure; logMAR: Logarithm of the minimum angle of resolution; $\mathrm{mmHg}$ : Millimetre (s) of mercury; PCIOL: Posterior chamber intraocular lens; 
PKP: Penetrating keratoplasty; ppV: Pars plana vitrectomy; TVT study: Tube Versus Trabeculectomy study; VA: Visual acuity

\section{Acknowledgements}

Not applicable.

\section{Funding}

We acknowledge financial support by Land Schleswig-Holstein within the funding programme Open Access Publikationfonds.

\section{Availability of data and materials}

The datasets used and/or analysed during the current study are available from the corresponding author on reasonable request.

\section{Authors' contributions}

All authors have participated directly in planning and execution of the work and have approved the final version of the manuscript. KP: acquisition and analysis of data, drafting and writing the article; MS: acquisition of data, final approval; FT: participated in the data collection and analysis; JR: participated in the design of the study and revised the article critically for important intellectual content; BN conception and design, helped to draft the manuscript.

\section{Ethics approval and consent to participate}

This study adhered to the tenets of the Declaration of Helsinki. For this retrospective type of study formal consent is not required according the regulations of the IRB Universitiy Medical Center Schleswig-Holstein.

\section{Consent for publication}

Not applicable.

\section{Competing interests}

The authors declare that they have no competing interests.

\section{Publisher's Note}

Springer Nature remains neutral with regard to jurisdictional claims in published maps and institutional affiliations.

Received: 10 January 2018 Accepted: 2 January 2019

Published online: 10 January 2019

\section{References}

1. Quigley HA, Broman AT. The number of people with glaucoma worldwide in 2010 and 2020. Br J Ophthalmol. 2006:90:262-7.

2. Kass MA, Heuer DK, Higginbotham EJ, Johnson CA, Keltner JL, Miller JP, et al. The ocular hypertension treatment study: a randomized trial determines that topical ocular hypotensive medication delays or prevents the onset of primary open-angle glaucoma. Arch Ophthalmol. 2002;120:701-13.

3. Leske MC, Heijl A, Hyman L, Bengtsson B, Dong L, Yang Z, et al. Predictors of long-term progression in the early manifest glaucoma treatment trial. Ophthalmology. 2007;114:1965-72.

4. Gedde SJ, Singh K, Schiffman JC, Feuer WJ. Tube versus trabeculectomy study group. The tube versus trabeculectomy study: interpretation of results and application to clinical practice. Curr Opin Ophthalmol. 2012;23:118-26.

5. Schwartz KS, Lee RK, Gedde SJ. Glaucoma drainage implants: a critical comparison of types. Curr Opin Ophthalmol. 2006;17:181-9.

6. Budenz DL, Barton K, Gedde SJ, Feuer WJ, Schiffman J, et al. Ahmed Baerveldt comparison study group. Five-year treatment outcomes in the Ahmed Baerveldt comparison study. Ophthalmology. 2015:122(2):308-16.

7. Tsai JC, Johnson CC, Kammer JA, Dietrich MS. The Ahmed shunt versus the Baerveldt shunt for refractory glaucoma II: longer-term outcomes from a single-surgeon. Ophthalmology. 2006;113:913-7.

8. Wang JC, See JL, Chew PT. Experience with the use of Baerveldt and Ahmed glaucoma drainage implants in an Asian population. Ophthalmology. 2004;111:1383-8.

9. Christiakis PG, Tsai JC, Kalenak JW, Zurakowski D, Cantor LB, Kammer JA, et al. Ahmed II. The Ahmed versus Baerveldt study: three-year treatment outcomes. Ophthalmology. 2013;120(11):2232-40.

10. Sidoti PA, Mosny AY, Ritterband DC, Seedor JA. Pars plana tube insertion of glaucoma drainage implants and penetrating keratoplasty in patients with coexisting glaucoma and corneal disease. Ophthalmology. 2001;108:1050-8.
11. Lloyd MA, Baerveldt G, Heuer DK, Minckler DS, Martone JF. Initial clinical experience with the Baerveldt implant in complicated glaucomas. Ophthalmology. 1994;101:640-50.

12. Fechtner RD, Singh K. Maximal glaucoma therapy. J Glaucoma. 2001;10:S73-5.

13. Assaad MH, Baerveldt G, Rockwood EJ. Glaucoma drainage devices: pros and cons. Curr Opin Ophthalmol. 1999:10:147-53.

14. Ramulu PY, Corcoran KJ, Corcoran SL, Robin AL. Utilization of various glaucoma surgeries and procedures in Medicare beneficiaries from 1995 to 2004. Ophthalmology. 2007;114:2265-70.

15. Rososinski A, Wechsler D, Grigg J. Retrospective review of pars plana versus anterior chamber placement of Baerveldt glaucoma drainage device. J Glaucoma. 2015;24(2):95-9.

16. DeGuzman MHPU, Valencia A, Farinelli AC. Pars plana insertion of glaucoma drainage devices for refractory glaucoma. Clin Exp Ophthalmol. 2006;34: $102-7$.

17. Souza C, Tran DH, Loman J, Law SK, Coleman AL, Caprioli J. Long-term outcomes of Ahmed glaucoma valve implantation in refractory glaucomas. Am J Ophthalmol. 2007;144(6):893-900.
Ready to submit your research? Choose BMC and benefit from:

- fast, convenient online submission

- thorough peer review by experienced researchers in your field

- rapid publication on acceptance

- support for research data, including large and complex data types

- gold Open Access which fosters wider collaboration and increased citations

- maximum visibility for your research: over $100 \mathrm{M}$ website views per year

At $\mathrm{BMC}$, research is always in progress.

Learn more biomedcentral.com/submissions 